\title{
Epidemiology of cancer-related venous thromboembolism
}

\author{
Ted Wun, MD, FACP ${ }^{\star}$ and \\ Division of Hematology and Oncology, Departments of Internal Medicine and Pathology, \\ University of California, Davis Cancer Center, 4501 X Street, Sacramento, CA 95187, USA \\ Richard H. White, MD, FACP \\ Division of General Internal Medicine, Department of Internal Medicine, University of California, \\ Davis, Sacramento, CA, USA
}

\begin{abstract}
Recent studies have better defined the epidemiology of venous thromboembolism (VTE) in cancer patients. The incidence is highest in patients who have metastatic disease at the time of presentation and who have fast growing, biologically aggressive cancers associated with a poor prognosis. The incidence is also high in patients with haematological cancers. Other specific risk factors that affect the incidence of VTE include undergoing invasive neurosurgery, the number of underlying chronic co-morbid conditions, and being of Asian/Pacific Islander decent (lower incidence). The incidence is highest in the first few months after diagnosis, which may reflect the biology of the cancer or medical interventions such as major surgery or start of chemotherapy. The development of VTE is clearly associated with decreased survival, and this effect is greater among patients initially diagnosed with local- or regional-stage cancer compared with patients with metastatic cancer, probably because VTE reflects the presence of a biologically aggressive cancer. Finally, a small percentage of patients with idiopathic VTE and no clinical or laboratory evidence of cancer may harbour an aggressive but 'occult' malignancy likely causally linked to the development of VTE.
\end{abstract}

\section{Keywords}

thromboembolism; epidemiology; race; ethnicity; pulmonary embolism; venous thrombosis

Cancer patients who develop venous thromboembolism (VTE) do not fare well. Early studies by Sorensen et al demonstrated that cancer patients who develop VTE have decreased survival compared with cancer patients without VTE, 1 and this has been observed repeatedly in subsequent studies.2-5 Understanding the epidemiology of VTE in cancer patients is important because it has implications regarding prognosis, treatment and prophylaxis.

\section{PREVALENCE OF VTE IN CANCER PATIENTS}

There is a very strong association between the presence of cancer and the development of acute VTE. In a large population-based epidemiological study, approximately $20 \%$ of all new cases of VTE are associated with underlying cancer, whereas $26 \%$ of incident cases had

\footnotetext{
*Corresponding author. Tel.: +1 916734 3772; fax: +1 916734 7946. E-mail address: twun@ ucdavis.edu.

Publisher's Disclaimer: This is a PDF file of an unedited manuscript that has been accepted for publication. As a service to our customers we are providing this early version of the manuscript. The manuscript will undergo copyediting, typesetting, and review of the resulting proof before it is published in its final citable form. Please note that during the production process errors may be discovered which could affect the content, and all legal disclaimers that apply to the journal pertain.
} 
idiopathic VTE.6,7 The relative risk of developing VTE is approximately seven times higher in patients with active cancer.8-14

With the proliferation of testing for both deep vein thrombosis and pulmonary embolism, 15 the frequency of asymptomatic VTE being detected by staging CT scans,16-19 and the ageing of the population, the proportion of all incident VTE cases associated with active cancer is likely to increase over the next decade. As more imaging tests are ordered in patients with cancer, the incidence of VTE will likely increase. Use of specific chemotherapeutic agents that strongly promote VTE, such as thalidomide, 20 will increase the incidence of cancer-associated VTE even further.

\section{INFLUENCE OF CANCER TYPE ON THE RISK OF VTE}

Most published studies that report the incidence of VTE in patients with specific types of cancer have the same type of case ascertainment bias, because they do not identify and follow all patients diagnosed with a certain type and stage of cancer. In studies performed in California, it was possible to overcome this bias because all patients diagnosed with cancer (except non-melanoma skin cancer and cervical carcinoma in situ) have to be reported to the California Cancer Registry (CCR). After identifying the cancer cases, the incidence of VTE diagnosed in these patients was used to determine the incidence of VTE by linking the CCR data to the California Patient Hospital Discharge Dataset using an encrypted form of their social security number.3 This analysis was performed for all cases diagnosed with cancer between 1993 and 1999; a time when low-molecular-weight heparin (LMWH) was not used for outpatient treatment of VTE.

Table 1 shows the cumulative incidence of VTE from the date of cancer diagnosis in California (accrued over 3 years), 3 the incidence of first-time VTE expressed as a rate per 100 patients living for 1 year, the 6-month incidence in a cohort with cancer from the Western Netherlands Cancer Registry (accrued over 16 years), 21 and the prevalence of firsttime VTE over a 6-month period in Medicare patients with cancer who required hospitalization between 1988 and 1990.22 Of note, the rate (per 100 patient-years) of VTE is particularly high in patients with clinically aggressive cancers like pancreas and stomach because a large proportion of these patients develop VTE but die within 1 year of cancer diagnosis, thus contributing, on average, far less than 1 year of follow-up time.

Although the three cohorts shown in Table 1 are not directly comparable, the cancers associated with the highest incidence of VTE are pancreas, brain, stomach and ovary, whereas prostate, breast and melanoma have a much lower incidence. There are clearly very large differences in the incidence of VTE between different types. For example, the incidence of VTE in pancreatic cancer patients is at least 10-fold higher than the rate in patients with prostate cancer.

\section{EFFECT OF INITIAL CANCER STAGE ON THE INCIDENCE OF VTE}

Table 2 shows the 1-year incidence rate of VTE in patients diagnosed with different stages of common cancers, excluding brain and leukaemias which are not routinely 'staged'. Large differences are seen in the incidence of VTE based on the initial cancer stage, particularly for bladder, melanoma and uterine cancer. Patients diagnosed with local-stage cancer, in general, have a very low incidence of VTE, whereas the incidence is much higher in patients diagnosed with metastatic disease. 


\section{INCIDENCE OF VTE AND BIOLOGICAL AGGRESSIVENESS OF CANCER}

The observed differences in the incidence of VTE between different cancer types correlate with the biology of the cancers. For example, there is a very strong correlation between the 1 -year fatality rate and the 1-year cumulative incidence of VTE $\left(r=0.81, R^{2}=0.64\right) .23$ These statistical measures mean that $64 \%$ of the variation observed in the incidence of VTE among different types of cancer can be explained by the difference in the 1-year death rate associated with each type of cancer. Assuming that death is a valid surrogate measure of the biological aggressiveness of a cancer, this means that the incidence of VTE correlates with biological aggressiveness.

In addition, among patients with different types of cancer, the incidence of VTE correlates with the percentage of patients with each type of cancer who are initially diagnosed with metastatic disease $\left(r=0.6, R^{2}=0.35\right) .23$ Thus, cancers that are biologically aggressive, as evidenced by early metastatic spread and short survival time, are the same cancers that have a high incidence of VTE. Adjusting for other risk factors, metastatic stage at the time of diagnosis is a strong independent risk factor for developing VTE within the first year after cancer diagnosis. $2-4,21,24,25$

It is commonly believed that mucinous adenocarcinomas are associated with a significantly higher incidence of VTE.8,26 This was borne out in detailed modelling of risk factors for VTE in patients with lung, colon and ovarian cancer.2,4,25 Another interesting finding was that patients with haematological malignancies, including lymphoma, leukaemia and myeloma, had relatively high rates of VTE.3,10,27 In these patients, however, it may well be that specific chemotherapeutic agents or the delivery of chemotherapy through central venous catheters and ports contributes strongly to the high incidence of VTE.

\section{TIME COURSE OF FIRST-TIME VTE AFTER INITIAL CANCER DIAGNOSIS}

The incidence of VTE is clearly higher in the first few months after cancer is diagnosed, and thereafter the incidence decreases with time.10,25 For example, Figure 1 shows the temporal incidence of VTE in patients with local, regional and metastatic colon cancer.2 The VTE incidence rate is much higher in the first 30-60 days after cancer diagnosis, with higher incidence rates in patients with metastatic cancer. The plots of the incidence of VTE over time using Kaplan-Meier life table plots was similar among patients with lung, 24 breast 25 and ovarian 4 cancer. The decrease in incidence rate over time is impressive. For example, among patients with colon cancer, the incidence rate (per 100 patient-years) of VTE falls from 5.0 during the first 6 months after cancer diagnosis to 1.4 in the 7-12 months after cancer diagnosis, and falls further to 0.6 by $1-2$ years after diagnosis. 2 Similar data have been reported by Blom et al in the Netherlands. 10

\section{RATE OF METASTATIC SPREAD, NOT EXTENT OF METASTATIC SPREAD, CORRELATES WITH VTE INCIDENCE}

The incidence of VTE correlates with the rate of growth and spread of the cancer, not the extent of spread of the cancer. In a detailed analysis of patients with colon cancer, 2 among the subset of patients who had regional-stage (metastases to regional lymph nodes) colon cancer initially, the cumulative incidence of VTE in the first year after diagnosis was 3.1\%, and $14.7 \%$ of these cases died in that year. However, during the second year of follow-up, a nearly equal number of cases died (13.6\%), presumably of cancer with metastatic spread, but only $0.5 \%$ of these patients were ever diagnosed with VTE. Thus, faster growing cancer, as evidenced by early recurrence and death, was associated with a higher rate of VTE. Very similar findings were reported in women with ovarian cancer.4 Among the women who 
were diagnosed with metastatic ovarian cancer, $15 \%$ died in the first 3 months and another 15\% died 4-12 months after cancer diagnosis. The incidence of VTE in the women who died $0-3$ months after cancer diagnosis was $27 \%$, compared with $10.7 \%$ among those that died 4-12 months after diagnosis. Although early major surgery and aggressive chemotherapy may contribute to the high early incidence of VTE after cancer diagnosis, as discussed in a later section, this is probably not the principal explanation.

Together, these findings suggest that development of VTE may be closely linked to tumour biology, and that it is the biological aggressiveness of the cancer manifested by the rate of growth or spread of the cancer that is most strongly associated with development of VTE, and not simply overall tumour burden. However, patients whose cancer transitions from apparently local-stage disease in remission to widespread metastatic spread are probably more likely to manifest VTE. A large percentage of cases diagnosed with local-stage cancer who develop VTE 1-2 years later have evidence of widespread metastatic disease.28

\section{EFFECT OF VTE ON SURVIVAL IN PATIENTS WITH DIFFERENT TYPES OF CANCER}

Sorenson et al were the first to report that cancer patients with VTE have reduced survival compared with cancer patients without VTE.1 In this population-based study from Denmark, patients with incident VTE who were concomitantly or subsequently diagnosed with cancer were compared with cancer patients who never developed VTE (control cohort). Patients and controls were matched for the type of cancer, age, gender and year of cancer diagnosis. Patients with cancer and VTE were more likely to have metastatic disease [prevalence ratio $=1.26,95 \%$ confidence interval (CI) 1.13-1.40]. The 1-year survival rate was only $12 \%$ in those patients who had cancer at the time of VTE, compared with 36\% in the control group. Patients diagnosed with cancer within 1 year of VTE also had a higher prevalence of metastatic disease and reduced survival.1

Sorensen et al's analysis did not specifically adjust for the cancer stage or the presence of chronic co-morbid medical conditions. As shown in Table 3, in studies utilizing the CCR database, the development of VTE was clearly associated with reduced survival, even after adjusting for age, race, gender, initial cancer stage and presence of chronic co-morbid medical conditions. 3 Thus, the reason why patients with VTE died earlier was not simply because these patients had a higher prevalence of metastatic disease that was associated with reduced mortality; rather, VTE itself was an independent predictor of mortality.

Although somewhat counterintuitive, the relative impact of VTE on survival was greatest among patients diagnosed with local-stage cancer, and was smallest among the cases that presented with metastatic cancer.2,3,24,25 Moreover, the magnitude of this unfavourable effect of VTE on survival increased as the time since cancer diagnosis increased. Figure 2a shows the survival of all patients who had local-stage breast cancer at cancer diagnosis and who either did or did not develop VTE within 2 years. This survival plot is somewhat difficult to interpret because it does not show when the patients developed VTE relative to cancer diagnosis. Figure $2 \mathrm{~b}$ compares the survival of patients with local-stage breast cancer who developed VTE with control cancer patients who did not develop VTE from the date of the VTE event rather than the date of cancer diagnosis. Control patients were matched for being alive the same number of days after cancer diagnosis as the patients with VTE, as well as age, race and the number of chronic medical co-morbidities. Interestingly, the effect of VTE on reduced survival is only apparent for the first 2-3 months after VTE diagnosis.

To further analyse the effect of VTE, Kaplan-Meier plots were generated for patients who developed VTE during different time intervals after the initial cancer diagnosis date. Figures 
$3 a, 3 b$ and $3 c$ show the survival of breast cancer patients who developed VTE 0-6 months, 7-12 months and 13-24 months, respectively, after cancer diagnosis. Although only a small number of patients developed VTE 6 months to 2 years after being diagnosed with breast cancer, a significant proportion of these patients died within 3 months of VTE. Review of hospital discharge codes and death certificates indicated that many, but not all, of these cases died of breast cancer.28 One reason why development of VTE appears to be more strongly associated with reduced survival among patients diagnosed with early-stage cancer is that in some patients, development of VTE may reflect the presence or emergence of a biologically aggressive cancer, or it may reflect the effect of ongoing hormonal or chemotherapy regimens. The same pattern was also seen in patients with colon and lung cancer.29

The finding that most deaths associated with VTE occurred in the first 60-90 days after VTE diagnosis suggests that development of the VTE may cause death directly by massive pulmonary embolization or anticoagulant-related bleeding, or it may simply reflect the presence of significant and serious underlying co-morbidity. Recent studies have shown that co-morbidities (number and severity) are independent predictors of survival in cancer patients (see below).30,31 Interestingly, among the 80\% of VTE patients who survived for more than 90 days after VTE diagnosis, VTE had little impact on survival. These latter cases of VTE may simply be 'background' cases that developed in patients who were essentially cured of breast cancer. Much more research is needed to determine the clinical implications and prognosis of VTE events that develop in patients diagnosed with local- or regional-stage cancer. It is clear, however, that cancer patients who develop VTE many months after their cancer diagnosis are a heterogeneous group. Some die very quickly due to VTE, metastatic cancer or chronic medical co-morbidity, whereas others appear to do very well.

\section{EFFECT OF MAJOR SURGERY ON THE INCIDENCE OF VTE}

A number of studies have definitively shown that patients with cancer who undergo a specific type of operation have a two- to four-fold higher incidence of postoperative VTE compared with patients without cancer.32 These data are generally interpreted as showing that surgery increases the risk of VTE in the postoperative period in cancer patients.33 This was certainly observed in a study analysing the effect of surgery in patients with glioma who underwent invasive neurosurgery.5 Compared with cases who did not undergo surgery, patients who underwent major neurosurgery or brain biopsy because of the presence of a glioma were $70 \%$ more likely to develop VTE within 3 months.

In contrast, Blom et al did not find an increased risk of VTE associated with surgery in cancer patients.21 Analysis of the California data in patients with breast, colon or ovarian cancer suggested that major surgery may actually be associated with a lower incidence of VTE compared with patients who did not undergo major surgery, even after adjustment for age, race, gender, cancer stage, and number of chronic co-morbidities. Patients undergoing gynaecological surgery for ovarian cancer had a $30 \%$ lower risk of developing VTE, patients undergoing breast surgery had a $40 \%$ lower risk of developing VTE, and patients with colorectal cancer had a $60 \%$ lower risk of developing VTE compared with patients who did not undergo major surgery. As these data did not include any information about thromboprophylaxis, it is not clear if this finding reflects aggressive peri-operative prophylaxis, a protective effect of tumour removal or some other reason. 


\section{EFFECT OF CHRONIC MEDICAL CO-MORBIDITIES ON THE INCIDENCE OF VTE}

The presence of chronic medical co-morbid conditions has a dramatic effect on the incidence of cancer-associated thrombosis and survival.34 Both the Charlson index 35 and the Elixhauser index 36 are widely used software programs that identify important medical conditions, such as chronic renal disease, chronic liver disease, hypertension, chronic heart failure, psychiatric disease etc. The Elixhauser index identifies 29 different conditions, but this can be modified to eliminate identification of disorders that are inappropriate, such as presence or absence of cancer, or conditions that may overlap with acute medical illness, e.g. anaemia, electrolyte disorder or coagulapathy.

In a detailed analysis of risk factors associated with development of VTE for colorectal cancer, the strongest risk factor was the metastatic stage at the time of diagnosis [hazard ratio $(\mathrm{HR})=3.2,95 \%$ CI 2.8-3.8), but the second strongest risk factor was the presence of three or more chronic medical conditions ( $\mathrm{HR}=2.0,95 \% \mathrm{CI} 1.7-2.3) .2 \mathrm{In}$ a similar analysis of risk factors in patients with breast cancer, 25 ovarian cancer 4 and brain gliomas, 5 there was a steady increase in the risk of developing VTE as the number of chronic co-morbid conditions increased (Table 4). The presence of three or more chronic medical conditions was the strongest risk factor for development of VTE among the patients with gliomas and ovarian cancer, whereas metastatic cancer was the strongest risk factor among patients with breast or colon cancer. For cancer types associated with a low proportion of cases being diagnosed with metastatic disease (e.g. breast and prostate cancer), the presence of metastatic disease was the strongest risk factor for VTE. However, for cancers associated with a high proportion of cases presenting with metastatic disease (e.g. pancreas and gastric), the presence of multiple co-morbidities became the strongest predictor of VTE. These findings suggest that the risk of developing VTE depends on both the prothrombotic strength of the cancer and the prothrombotic propensity of the host, which probably increase as the number of chronic medical conditions increases. Future research is needed to determine which chronic medical conditions are the strongest risk factors for cancerassociated thrombosis.

\section{EFFECT OF ANTINEOPLASTIC AND SUPPORTIVE CARE THERAPY}

Many systemic cancer treatments predispose to VTE. Conventional cytotoxic chemotherapy is associated with an increased risk of VTE.37-40 Newer agents such as thalidomide20,41 and lenalidomide 42,43 have been associated with increased VTE, especially when combined with high-dose dexamethasone for the treatment of multiple myeloma. Routine thromboprophylaxis is recommended when using these combinations. Anti-angiogenic agents are associated with a higher risk of both arterial and venous thrombosis, as well as an increased risk of bleeding. 44 Use of the erythropoietic-stimulating agents erythropoietin and darbepoietin increases the incidence of VTE in cancer patients,39,45-47 especially for those receiving concurrent chemotherapy and radiation.46,48 Myeloid growth factors also appear to increase the rate of VTE.39 Curiously, the risk of VTE associated with hospitalization has increased over the last decade; a time associated with increased use of medical thromboprophylaxis.49 In part, this higher incidence of VTE may reflect more prevalent use of indwelling upper extremity catheters, which lead to upper extremity VTE in a modest percentage of cases.50 Unfortunately, use of prophylactic doses of heparin or LMWH does not appear to prevent these VTE events.51-53 However, this trend may also reflect changes in case mix, with sicker patients who have more chronic co-morbidities being hospitalized compared with previous decades. 


\section{BIOMARKERS, THROMBOPHILIA AND A PREDICTIVE MODEL FOR CANCER-ASSOCIATED VTE}

In addition to the epidemiological and treatment-related risk factors discussed, laboratory biomarkers that are associated with an increased risk of VTE patients might further identify a high-risk cancer population. As genetic predisposition to thrombosis is relatively prevalent in the general population, it is possible that inheritance of these thrombophilia genes might interact with cancer to increase the risk of VTE. Blom et al, in a case-control study of patients with incident VTE at six anticoagulation clinics in the Netherlands, found an increased risk of thrombosis in carriers of Factor V Leiden and the prothrombin gene mutation (Factor II mutation) compared with cancer patients without these mutations.10 However, the utility of screening for underlying thrombophilia in cancer patients to identify higher-risk groups has not been established.

Recent work, predominantly in the outpatient setting, has described several promising biomarkers that may be predictive of cancer-associated VTE. Khorana et al have shown that a prechemotherapy platelet count of $>350 \times 10^{9} / \mathrm{L}$ or leukocyte count $>11 \times 10^{9} / \mathrm{L}$ were associated with an increased risk of thrombosis in a predominantly outpatient population.54 Higher D-dimer levels have also been associated with an increased risk of malignancy in patients presenting with VTE.55 Whether or not elevated D-dimer levels can predict for those at higher risk for cancer-associated VTE has not been demonstrated. A single study demonstrated that elevated C-reactive protein (CRP) levels predicted for VTE.56 If confirmed, CRP levels might be useful as the test is now more widely available.

P-selectin is a platelet adhesion molecule important in cell-cell interactions. Elevated levels of soluble P-selectin in plasma reflects platelet activation and may serve as a surrogate for greater platelet-tumour cell and/or platelet-monocyte interactions, both of which promote thrombosis.57 A recent report showed that a soluble P-selection level $>75^{\text {th }}$ percentile was associated with an HR of 2.6 (95\% CI 1.4-4.9) for cancer-associated thrombosis. 58 Microparticles are vesicles derived from many cell types upon activation. Sources in plasma include platelets, red cells, monocytes and endothelial cells. In cancer patients, the microparticles can be tumour derived, express tissue factor and be implicated in pathogenesis.59 Elevated levels of microparticles have been found in patients with cancer and thrombosis, but the assays are not standardized and their predictive value requires prospective study.

\section{IDENTIFICATION OF PATIENTS AT HIGH RISK FOR CANCER-ASSOCIATED VTE}

In addition to the inherent morbidity of VTE, treatment of VTE in patients with cancer is more difficult and is associated with considerable morbidity.60,61 Thus, identification of a high-risk subgroup of patients for primary thromboprophylaxis may be justified. In order to identify those patients who may benefit from primary thromboprophylaxis, the highest-risk patients must be identified. The information that has been presented about the effect of cancer type, cancer stage, cancer histology and cancer treatment on the incidence of VTE, combined with the effects of age, race, gender and presence of other chronic medical comorbidities, provides a framework for stratifying those patients at highest risk for developing VTE.

Recently, Khorana et al devised a simple risk scoring system to predict incident VTE in ambulatory patients with cancer.54 Five predictive variables were identified in a stageadjusted multivariate model in the development cohort: site of cancer, platelet count $\geq 350$ $000 / \mathrm{mm}^{3}$, haemoglobin $<10 \mathrm{~g} / \mathrm{dL}$ and/or use of erythropoietin, leukocyte count $>11000$ / 
$\mathrm{mm}^{3}$ and body mass index 235 . High-risk cancers included brain, pancreas, kidney, stomach, lung, gynaecological, lymphoma and myeloma. Rates of VTE in the development and validation cohorts, respectively, were $0.8 \%$ and $0.3 \%$ in the low-risk category (score $=0$ ), $1.8 \%$ and $2 \%$ in the intermediate-risk category (score $=1-2$ ), and $7.1 \%$ and $6.7 \%$ in the highrisk category (score 23 ) over a median period of 2.5 months (C-statistic $=0.7$ for both cohorts). The high rate of symptomatic VTE observed in the high-risk subgroup of patients is similar to that seen in hospitalized or surgical patients for whom prophylaxis is both safe and effective. A model-based approach incorporating a clinical prediction tool of readily available data may be the most efficient way to identify cancer patients at highest risk for VTE, allowing the study of various prophylactic strategies in those patients.

\section{RECURRENT VTE AND CANCER}

Patients with cancer that develop VTE are at higher risk for recurrent VTE than those without cancer, despite anticoagulation for secondary prophylaxis. In a retrospective cohort study of patients with incident VTE residing in Olmstead County, MN, USA, Heit et al reported an HR of 2.2 (95\% CI 1.6-3.1) for recurrence associated with active neoplasms in multivariate analysis.62 This was increased to 4.2 (95\% CI 2.6-7.0) if the patient was receiving chemotherapy. Hutten et al made a similar observation in a retrospective analysis of two multicentre clinical trials: the rate of recurrent VTE was 27.1/100 patient-years (95\% CI 14.8-45.4) for those with cancer vs 9.0/100 patient-years (95\% CI 5.6-13.8) for those without malignancy. 63 This study also showed an increased rate of bleeding complications with oral anticoagulation in cancer patients.

Prandoni et al performed a prospective cohort study of consecutive patients with incident VTE and compared the incidence of recurrence and bleeding for those with and without cancer at the time of VTE.60 Patients were given heparin followed by warfarin. The duration of anticoagulation was not prespecified, but was longer in patients with malignancy (median 224 days) than without (median 90 days). The 12-month cumulative incidence of recurrent VTE in the group with cancer was $20.7 \%$ (95\% CI 15.6-25.8\%) vs $6.8 \%$ (95\% CI $3.9-9.7 \%$ ) in those without malignancy. Adjusted for age, cancer was associated with an HR of 3.2 (95\% CI 1.9-5.4) for recurrent VTE. This was observed despite the fact that international normalized ratio values were more often within or above the therapeutic range in the patients with recurrent VTE and cancer than in those with recurrence and no cancer. The rate of recurrence was directly associated with tumour burden as prospectively assessed by the investigators. This study also confirmed that the risk of major bleeding was also higher for patients with extensive cancer on warfarin anticoagulation.

\section{USE OF LMWH TO TREAT PATIENTS WITH CANCER}

Some studies have suggested that thromboprophylaxis using LMWH may improve survival in patients with cancer who develop VTE. An early post-hoc analysis of a clinical trial reported that patients with active cancer who developed symptomatic VTE and who were treated with LMWH had improved short-term mortality compared with patients treated with warfarin.64 This study spurred considerable interest, leading to similar analyses of other clinical trials of LMWH,65-68 and even the design of a clinical trial (FAMOUS).69 The result of this primary prevention study suggested that moderate prophylactic doses of LMWH (5000 U daltaparin once daily) had no significant benefit in patients who had advanced-stage cancer, but possibly some long-term survival benefit in patients who had less extensive disease and who survived for over 17 months. Another clinical trial (CLOT study) focused on the secondary prevention of VTE in patients with cancer. A post-hoc analysis showed that use of LMWH (daltaparin, $150 \mathrm{U} / \mathrm{kg} / \mathrm{day}$ ) for 6 months significantly improved survival among patients who did not initially have metastatic cancer.70 The 
number of subjects enrolled in this study was too small to determine if the benefit occurred in patients with one specific type of cancer.

\section{SUMMARY AND CONCLUSIONS}

VTE is a common complication of cancer and is associated with reduced survival. In patients with cancer, the risk of first-time VTE is highly variable and depends primarily on the tumour type, metastatic stage at the time of diagnosis, presence of concurrent chronic medical conditions, and clinical characteristics including haemoglobin and platelet count, and use of specific chemotherapeutic agents. As the incidence of VTE in cancer patients who require hospitalization is very high, these patients should always receive thromboprophylaxis with either unfractionated heparin, LMWH or fondaparinux.

It is not known whether or not other patients at highest risk for developing thromboembolism should receive primary prophylaxis. It is likely that the absolute and relative benefit of primary thromboprophylaxis will vary greatly amongst different patient groups. Clinical trials are needed to address this important question. Such studies could focus on specific high-risk groups (e.g. glioma patients undergoing surgery or patients receiving thrombogenic antineoplastic therapy). Another strategy would be identify highrisk groups using a risk stratification tool similar to that suggested by Khorana et al.54 It appears that the greatest potential impact of primary prophylaxis would be in patients initially diagnosed with advanced disease, 71 particularly those who are candidates for chemotherapy.72-74 However, another subgroup of patients who may warrant primary thromboprophylaxis is patients initially diagnosed with local- or regional-stage cancer who progress and develop metastatic cancer.3,70 Trials of thromboprophylaxis in patients with cancer should determine the effect of prophylaxis on the incidence of both VTE and bleeding, and also progression-free and overall survival.

Patients with cancer and incident VTE are at high risk for recurrence and bleeding complications. Randomized studies have shown that prolonged (6 months) treatment with LMWH results in both lower VTE recurrence rates and less bleeding. Thus, LMWH is the therapy of choice for treatment of VTE in patients with cancer. However, the optimal duration of therapy for patients with active cancer has not been determined.

\section{Practice points}

- patients who present initially with metastatic cancer have the highest incidence of VTE

- biologically aggressive cancers that are associated with reduced 1-year survival have the highest incidence of VTE (e.g. pancreatic cancer)

- more indolent, slower growing cancers, like breast and prostate cancer, have a significantly lower incidence of VTE

- the incidence of VTE is highest in the first 2-3 months after cancer diagnosis

- VTE has a negative impact on survival in patients with cancer. Although prophylactic heparin is theoretically most beneficial in patients with early metastatic spread, clinical studies have not shown that prophylaxis affects survival

- the effect of major surgery on the incidence of VTE varies with cancer type

- therapies used to treat patients with cancer, including antineoplastic and supportive care drugs, can increase the risk of VTE

- it may be possible to identify cancer patients at highest risk for VTE 
- cancer patients who develop VTE have a higher risk of recurrent VTE and bleeding than patients without cancer, despite anticoagulation

- LMWHs are the therapy of choice for patients with cancer-associated thrombosis

\section{Research agenda}

- develop and validate predictive models for VTE in patients with cancer to identify a high-risk population

- more studies are needed to determine if aggressive thromboprophylaxis with heparin/LMWH or an anti-Xa inhibitor reduces the incidence of lower extremity deep vein thrombosis or pulmonary embolism in high-risk patients without causing excessive bleeding

- determine if postoperative VTE in cancer patients has a lower incidence of recurrent VTE compared with patients who have spontaneous VTE

- $\quad$ studies are needed to determine if asymptomatic VTE detected by screening or staging is associated with symptomatic recurrence and reduced survival

\section{Acknowledgments}

This publication was made possible by Grant Number UL1 RR024146 from the National Center for Research Resources (NCRR), a component of the National Institutes of Health (NIH), and NIH Roadmap for Medical Research. Its contents are solely the responsibility of the authors and do not necessarily represent the official view of NCRR or NIH. The Hibbard Williams Endowment for General Medicine Research also supported this work.

\section{References}

1. Sorensen HT, Mellemkjaer L, Olsen JH, Baron JA. Prognosis of cancers associated with venous thromboembolism. N Engl J Med. 2000; 343:1846-1850. [PubMed: 11117976]

2. Alcalay A, Wun T, Khatri V, et al. Venous thromboembolism in patients with colorectal cancer: incidence and effect on survival. J Clin Oncol. 2006; 24:1112-1118. [PubMed: 16505431]

3. Chew HK, Wun T, Harvey D, Zhou H, White RH. Incidence of venous thromboembolism and its effect on survival among patients with common cancers. Arch Intern Med. 2006; 166:458-464. [PubMed: 16505267]

4. Rodriguez AO, Wun T, Chew H, Zhou H, Harvey D, White RH. Venous thromboembolism in ovarian cancer. Gynecol Oncol. 2007; 105:784-790. [PubMed: 17408726]

5. Semrad TJ, O'Donnell R, Wun T, et al. Epidemiology of venous thromboembolism in 9489 patients with malignant glioma. J Neurosurg. 2007; 106:601-608. [PubMed: 17432710]

6. White RH, Zhou H, Murin S, Harvey D. Effect of ethnicity and gender on the incidence of venous thromboembolism in a diverse population in California in 1996. Thromb Haemost. 2005; 93:298305. [PubMed: 15711746]

7. Heit JA, O'Fallon WM, Petterson TM, et al. Relative impact of risk factors for deep vein thrombosis and pulmonary embolism: a population-based study. Arch Intern Med. 2002; 162:1245-1248. [PubMed: 12038942]

8. Buller HR, van Doormaal FF, van Sluis GL, Kamphuisen PW. Cancer and thrombosis: from molecular mechanisms to clinical presentations. J Thromb Haemost. 2007; 5 (Suppl 1):246-254. [PubMed: 17635733]

9. Varki A. Trousseau's syndrome: multiple definitions and multiple mechanisms. Blood. 2007; 110:1723-1729. [PubMed: 17496204]

10. Blom JW, Doggen CJ, Osanto S, Rosendaal FR. Malignancies, prothrombotic mutations, and the risk of venous thrombosis. JAMA. 2005; 293:715-722. [PubMed: 15701913]

11. Prandoni P, Falanga A, Piccioli A. Cancer and venous thromboembolism. Lancet Oncol. 2005; 6:401-410. [PubMed: 15925818] 
12. Rickles FR, Levine MN. Epidemiology of thrombosis in cancer. Acta Haematol. 2001; 106:6-12. [PubMed: 11549771]

13. Hansson PO, Welin L, Tibblin G, Eriksson H. Deep vein thrombosis and pulmonary embolism in the general population. 'The Study of Men Born in 1913'. Arch Intern Med. 1997; 157:16651670. [PubMed: 9250227]

14. Sallah S, Wan JY, Nguyen NP. Venous thrombosis in patients with solid tumors: determination of frequency and characteristics. Thromb Haemost. 2002; 87:575-579. [PubMed: 12008937]

15. DeMonaco NA, Dang Q, Kapoor WN, Ragni MV. Pulmonary embolism incidence is increasing with use of spiral computed tomography. Am J Med. 2008; 121:611-617. [PubMed: 18589057]

16. Satoh T, Matsumoto K, Uno K, et al. Silent venous thromboembolism before treatment in endometrial cancer and the risk factors. Br J Cancer. 2008

17. Satoh T, Oki A, Uno K, et al. High incidence of silent venous thromboembolism before treatment in ovarian cancer. Br J Cancer. 2007; 97:1053-1057. [PubMed: 17895896]

18. O'Connell CL, Boswell WD, Duddalwar V, et al. Unsuspected pulmonary emboli in cancer patients: clinical correlates and relevance. J Clin Oncol. 2006; 24:4928-4932. [PubMed: 17050877]

19. Cronin CG, Lohan DG, Keane M, Roche C, Murphy JM. Prevalence and significance of asymptomatic venous thromboembolic disease found on oncologic staging CT. AJR Am J Roentgenol. 2007; 189:162-170. [PubMed: 17579167]

20. El Accaoui RN, Shamseddeen WA, Taher AT. Thalidomide and thrombosis. A meta-analysis. Thromb Haemost. 2007; 97:1031-1036. [PubMed: 17549307]

21. Blom JW, Vanderschoot JP, Oostindier MJ, Osanto S, van der Meer FJ, Rosendaal FR. Incidence of venous thrombosis in a large cohort of 66,329 cancer patients: results of a record linkage study. J Thromb Haemost. 2006; 4:529-535. [PubMed: 16460435]

22. Levitan N, Dowlati A, Remick SC, et al. Rates of initial and recurrent thromboembolic disease among patients with malignancy versus those without malignancy. Risk analysis using Medicare claims data. Medicine (Baltimore). 1999; 78:285-291. [PubMed: 10499070]

23. White, RH.; Wun, T. The burden of cancer-associated venous thromboembolism and its impact on cancer survival. In: Khorana, AA.; Francis, CW., editors. Cancer-associated Thrombosis: New Findings in Translational Science, Prevention, and Treatment. New York: Informa Healthcare, USA, Inc; 2008.

24. Chew HK, Davies AM, Wun T, Harvey D, Zhou H, White RH. The incidence of venous thromboembolism among patients with primary lung cancer. J Thromb Haemost. 2008; 6:601608. [PubMed: 18208538]

25. Chew HK, Wun T, Harvey DJ, Zhou H, White RH. Incidence of venous thromboembolism and the impact on survival in breast cancer patients. J Clin Oncol. 2007; 25:70-76. [PubMed: 17194906]

26. Falanga A, Rickles FR. Pathophysiology of the thrombophilic state in the cancer patient. Semin Thromb Hemost. 1999; 25:173-182. [PubMed: 10357085]

27. Elliott MA, Wolf RC, Hook CC, et al. Thromboembolism in adults with acute lymphoblastic leukemia during induction with L-asparaginase-containing multi-agent regimens: incidence, risk factors, and possible role of antithrombin. Leuk Lymphoma. 2004; 45:1545-1549. [PubMed: 15370205]

28. Wun T, Chew HK, Zhou H, Harvey D, White RH. Cause of death among patients with local or regional stage cancer of the breast, colon and lung who develop venous thromboembolism (VTE). Blood. 2006; 108:433a.

29. Wun T, Chew H, Zhou H, Harvey D, White RH. Venous thromboembolism (VTE) is associated with recurrent cancer in patients with initially non-metastatic breast, lung, and colon cancer. Thromb Res. 2007; 120:S175.

30. Extermann M. Interaction between comorbidity and cancer. Cancer Control. 2007; 14:13-22. [PubMed: 17242667]

31. Kendal WS. Dying with cancer: the influence of age, comorbidity, and cancer site. Cancer. 2008; 112:1354-1362. [PubMed: 18286532] 
32. White RH, Zhou H, Romano PS. Incidence of symptomatic venous thromboembolism after different elective or urgent surgical procedures. Thromb Haemost. 2003; 90:446-455. [PubMed: 12958614]

33. Prandoni P, Piccioli A, Girolami A. Cancer and venous thromboembolism: an overview. Haematologica. 1999; 84:437-445. [PubMed: 10329923]

34. Piccirillo JF, Tierney RM, Costas I, Grove L, Spitznagel EL Jr. Prognostic importance of comorbidity in a hospital-based cancer registry. JAMA. 2004; 291:2441-2447. [PubMed: 15161894]

35. Charlson M, Szatrowski TP, Peterson J, Gold J. Validation of a combined comorbidity index. J Clin Epidemiol. 1994; 47:1245-1251. [PubMed: 7722560]

36. Elixhauser A, Steiner C, Harris DR, Coffey RM. Comorbidity measures for use with administrative data. Med Care. 1998; 36:8-27. [PubMed: 9431328]

37. Otten HM, Mathijssen J, ten Cate H, et al. Symptomatic venous thromboembolism in cancer patients treated with chemotherapy: an underestimated phenomenon. Arch Intern Med. 2004; 164:190-194. [PubMed: 14744843]

38. Lee AY, Levine MN. The thrombophilic state induced by therapeutic agents in the cancer patient. Semin Thromb Hemost. 1999; 25:137-145. [PubMed: 10357081]

39. Khorana AA, Francis CW, Culakova E, Lyman GH. Risk factors for chemotherapy-associated venous thromboembolism in a prospective observational study. Cancer. 2005; 104:2822-2829. [PubMed: 16284987]

40. Haddad TC, Greeno EW. Chemotherapy-induced thrombosis. Thromb Res. 2006; 118:555-568. [PubMed: 16388837]

41. Alkindi S, Dennison D, Pathare A. Arterial and venous thrombotic complications with thalidomide in multiple myeloma. Arch Med Res. 2008; 39:257-258. [PubMed: 18164975]

42. Hirsh J. Risk of thrombosis with lenalidomide and its prevention with aspirin. Chest. 2007; 131:275-277. [PubMed: 17218586]

43. Palumbo A, Rajkumar SV, Dimopoulos MA, et al. Prevention of thalidomide- and lenalidomideassociated thrombosis in myeloma. Leukemia. 2008; 22:414-423. [PubMed: 18094721]

44. Kilickap S, Abali H, Celik I. Bevacizumab, bleeding, thrombosis, and warfarin. J Clin Oncol. 2003; 21:3542. author reply 3543. [PubMed: 12972536]

45. Bennett CL, Silver SM, Djulbegovic B, et al. Venous thromboembolism and mortality associated with recombinant erythropoietin and darbepoetin administration for the treatment of cancerassociated anemia. JAMA. 2008; 299:914-924. [PubMed: 18314434]

46. Wun T, Law L, Harvey D, Sieracki B, Scudder SA, Ryu JK. Increased incidence of symptomatic venous thrombosis in patients with cervical carcinoma treated with concurrent chemotherapy, radiation, and erythropoietin. Cancer. 2003; 98:1514-1520. [PubMed: 14508840]

47. Bohlius J, Wilson J, Seidenfeld J, et al. Recombinant human erythropoietins and cancer patients: updated meta-analysis of 57 studies including 9353 patients. J Natl Cancer Inst. 2006; 98:708-714. [PubMed: 16705125]

48. Lavey RS, Liu PY, Greer BE, et al. Recombinant human erythropoietin as an adjunct to radiation therapy and cisplatin for stage IIB-IVA carcinoma of the cervix: a Southwest Oncology Group study. Gynecol Oncol. 2004; 95:145-151. [PubMed: 15385124]

49. Khorana AA, Francis CW, Culakova E, Kuderer NM, Lyman GH. Frequency, risk factors, and trends for venous thromboembolism among hospitalized cancer patients. Cancer. 2007; 110:23392346. [PubMed: 17918266]

50. Verso M, Agnelli G. Venous thromboembolism associated with long-term use of central venous catheters in cancer patients. J Clin Oncol. 2003; 21:3665-3675. [PubMed: 14512399]

51. Verso M, Agnelli G, Bertoglio S, et al. Enoxaparin for the prevention of venous thromboembolism associated with central vein catheter: a double-blind, placebo-controlled, randomized study in cancer patients. J Clin Oncol. 2005; 23:4057-4062. [PubMed: 15767643]

52. Mismetti P, Mille D, Laporte S, et al. Low-molecular-weight heparin (nadroparin) and very low doses of warfarin in the prevention of upper extremity thrombosis in cancer patients with indwelling long-term central venous catheters: a pilot randomized trial. Haematologica. 2003; 88:67-73. [PubMed: 12551829] 
53. Niers TM, Di Nisio M, Klerk CP, Baarslag HJ, Buller HR, Biemond BJ. Prevention of catheterrelated venous thrombosis with nadroparin in patients receiving chemotherapy for hematologic malignancies: a randomized, placebo-controlled study. J Thromb Haemost. 2007; 5:1878-1882. [PubMed: 17723127]

54. Khorana AA, Kuderer NM, Culakova E, Lyman GH, Francis CW. Development and validation of a predictive model for chemotherapy-associated thrombosis. Blood. 2008; 111:4902-4907. [PubMed: 18216292]

55. Falanga A. The predictive value of D-dimer measurement for cancer in patients with deep vein thrombosis. Haematologica. 2005; 90:149. [PubMed: 15713577]

56. Kroger K, Weiland D, Ose C, et al. Risk factors for venous thromboembolic events in cancer patients. Ann Oncol. 2006; 17:297-303. [PubMed: 16282243]

57. Chen M, Geng JG. P-selectin mediates adhesion of leukocytes, platelets, and cancer cells in inflammation, thrombosis, and cancer growth and metastasis. Arch Immunol Ther Exp (Warsz). 2006; 54:75-84. [PubMed: 16648968]

58. Ay C, Simanek R, Vormittag R, et al. High plasma levels of soluble P-selectin are predictive of venous thromboembolism in cancer patients: results from the Vienna Cancer and Thrombosis Study (CATS). Blood. 2008; 112:2703-2708. [PubMed: 18539899]

59. Tesselaar ME, Romijn FP, Van Der Linden IK, Prins FA, Bertina RM, Osanto S. Microparticleassociated tissue factor activity: a link between cancer and thrombosis? J Thromb Haemost. 2007; 5:520-527. [PubMed: 17166244]

60. Prandoni P, Lensing AW, Piccioli A, et al. Recurrent venous thromboembolism and bleeding complications during anticoagulant treatment in patients with cancer and venous thrombosis. Blood. 2002; 100:3484-3488. [PubMed: 12393647]

61. Bona RD, Hickey AD, Wallace DM. Efficacy and safety of oral anticoagulation in patients with cancer. Thromb Haemost. 1997; 78:137-140. [PubMed: 9198143]

62. Heit JA, Mohr DN, Silverstein MD, Petterson TM, O'Fallon WM, Melton LJ 3rd. Predictors of recurrence after deep vein thrombosis and pulmonary embolism: a population-based cohort study. Arch Intern Med. 2000; 160:761-768. [PubMed: 10737275]

63. Hutten BA, Prins MH, Gent M, Ginsberg J, Tijssen JG, Buller HR. Incidence of recurrent thromboembolic and bleeding complications among patients with venous thromboembolism in relation to both malignancy and achieved international normalized ratio: a retrospective analysis. $\mathbf{J}$ Clin Oncol. 2000; 18:3078-3083. [PubMed: 10963635]

64. Green D, Hull RD, Brant R, Pineo GF. Lower mortality in cancer patients treated with lowmolecular-weight versus standard heparin. Lancet. 1992; 339:1476. [PubMed: 1351142]

65. Gould MK, Dembitzer AD, Doyle RL, Hastie TJ, Garber AM. Low-molecular-weight heparins compared with unfractionated heparin for treatment of acute deep venous thrombosis. A metaanalysis of randomized, controlled trials. Ann Intern Med. 1999; 130:800-809. [PubMed: 10366369]

66. Hettiarachchi RJ, Smorenburg SM, Ginsberg J, Levine M, Prins MH, Buller HR. Do heparins do more than just treat thrombosis? The influence of heparins on cancer spread. Thromb Haemost. 1999; 82:947-952. [PubMed: 10605808]

67. Smorenburg SM, Hettiarachchi RJ, Vink R, Buller HR. The effects of unfractionated heparin on survival in patients with malignancy - a systematic review. Thromb Haemost. 1999; 82:16001604. [PubMed: 10613641]

68. Siragusa S, Cosmi B, Piovella F, Hirsh J, Ginsberg JS. Low-molecular-weight heparins and unfractionated heparin in the treatment of patients with acute venous thromboembolism: results of a meta-analysis. Am J Med. 1996; 100:269-277. [PubMed: 8629671]

69. Kakkar AK, Levine MN, Kadziola Z, et al. Low molecular weight heparin, therapy with dalteparin, and survival in advanced cancer: the Fragmin Advanced Malignancy Outcome Study (FAMOUS). J Clin Oncol. 2004; 22:1944-1948. [PubMed: 15143088]

70. Lee AY, Rickles FR, Julian JA, et al. Randomized comparison of low molecular weight heparin and coumarin derivatives on the survival of patients with cancer and venous thromboembolism. $\mathrm{J}$ Clin Oncol. 2005; 23:2123-2129. [PubMed: 15699480] 
71. Sgouros J, Maraveyas A. Excess premature (3-month) mortality in advanced pancreatic cancer could be related to fatal vascular thromboembolic events. A hypothesis based on a systematic review of phase III chemotherapy studies in advanced pancreatic cancer. Acta Oncol. 2007:1-10. [PubMed: 17924209]

72. Altinbas M, Coskun HS, Er O, et al. A randomized clinical trial of combination chemotherapy with and without low-molecular-weight heparin in small cell lung cancer. J Thromb Haemost. 2004; 2:1266-1271. [PubMed: 15304029]

73. Khorana AA, Francis CW, Culakova E, Kuderer NM, Lyman GH. Thromboembolism is a leading cause of death in cancer patients receiving outpatient chemotherapy. J Thromb Haemost. 2007; 5:632-634. [PubMed: 17319909]

74. Lee AY. Deep vein thrombosis and cancer: survival, recurrence, and anticoagulant choices. Dis Mon. 2005; 51:150-157. [PubMed: 15900267] 


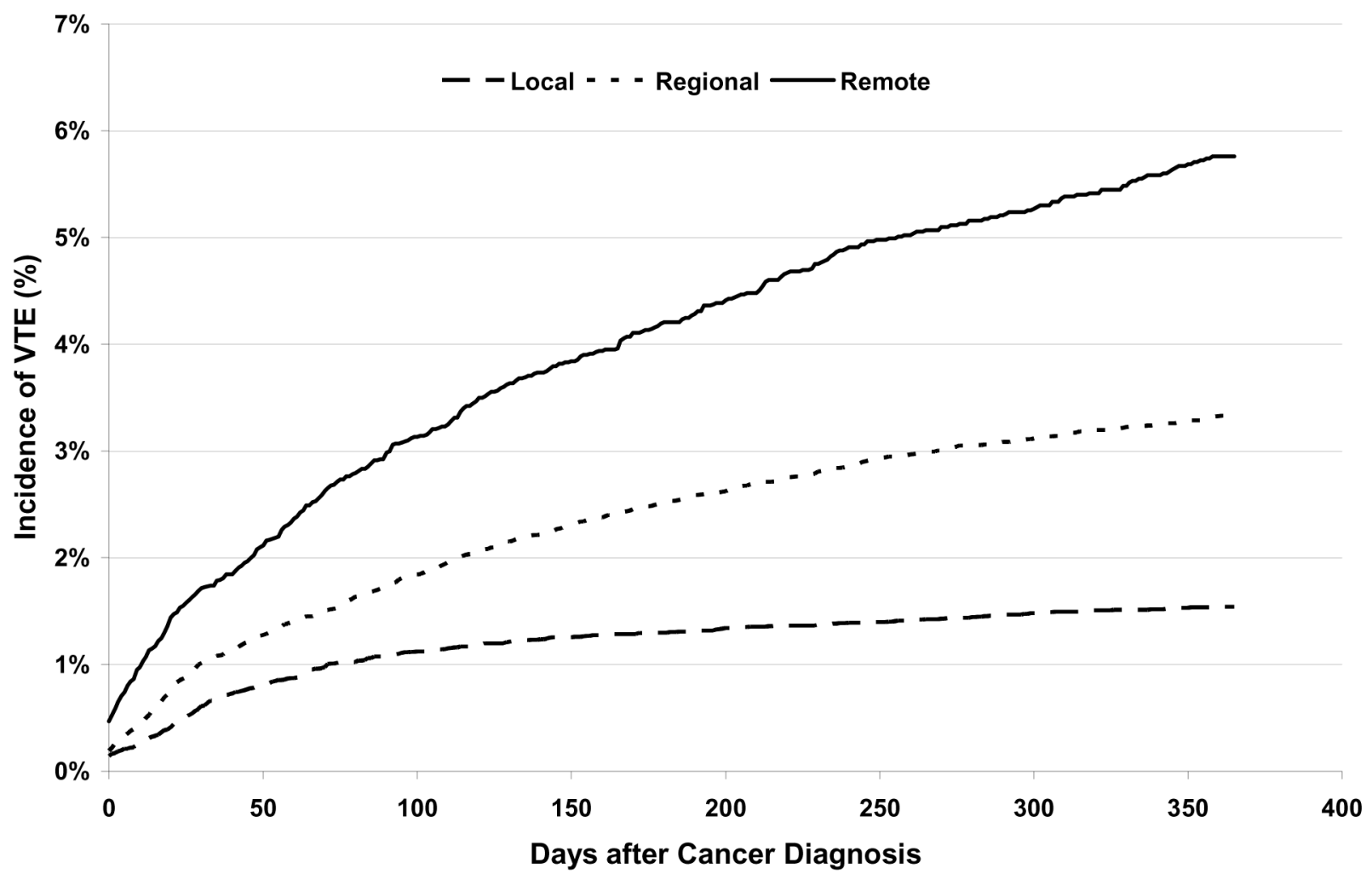

Figure 1.

Kaplan-Meier plot of the incidence of venous thromboembolism (VTE) in patients with colon cancer, stratified by initial cancer stage. 

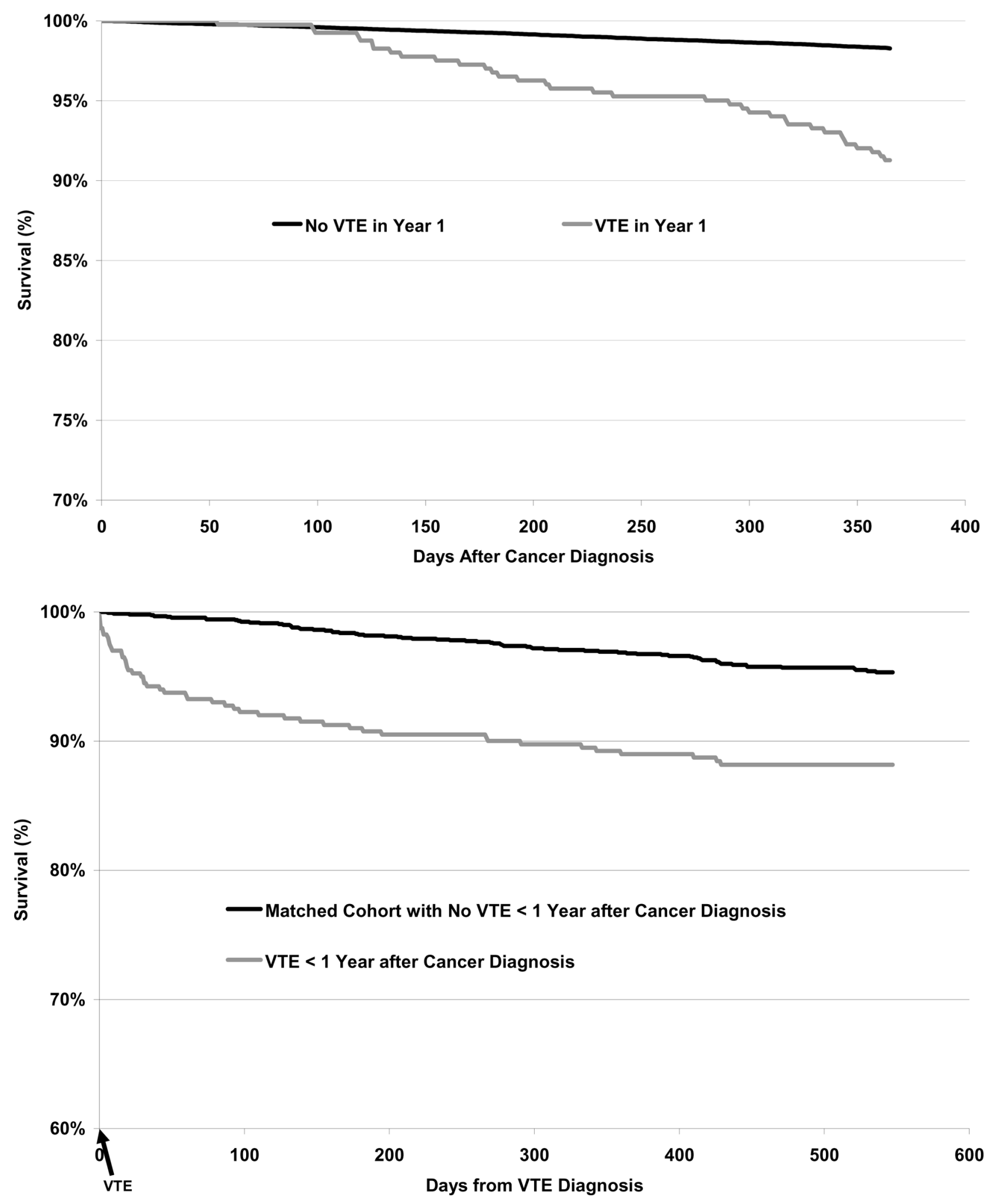

Figure 2.

(a) Survival from cancer diagnosis date among breast cancer patients with local-stage cancer who did or did not develop venous thromboembolism (VTE) within 1 year. (b) Comparison 
of survival from the date of diagnosis of VTE among breast cancer patients who developed VTE within 1 year of the diagnosis of local-stage breast cancer vs a matched sample of cases who were not diagnosed with VTE. 

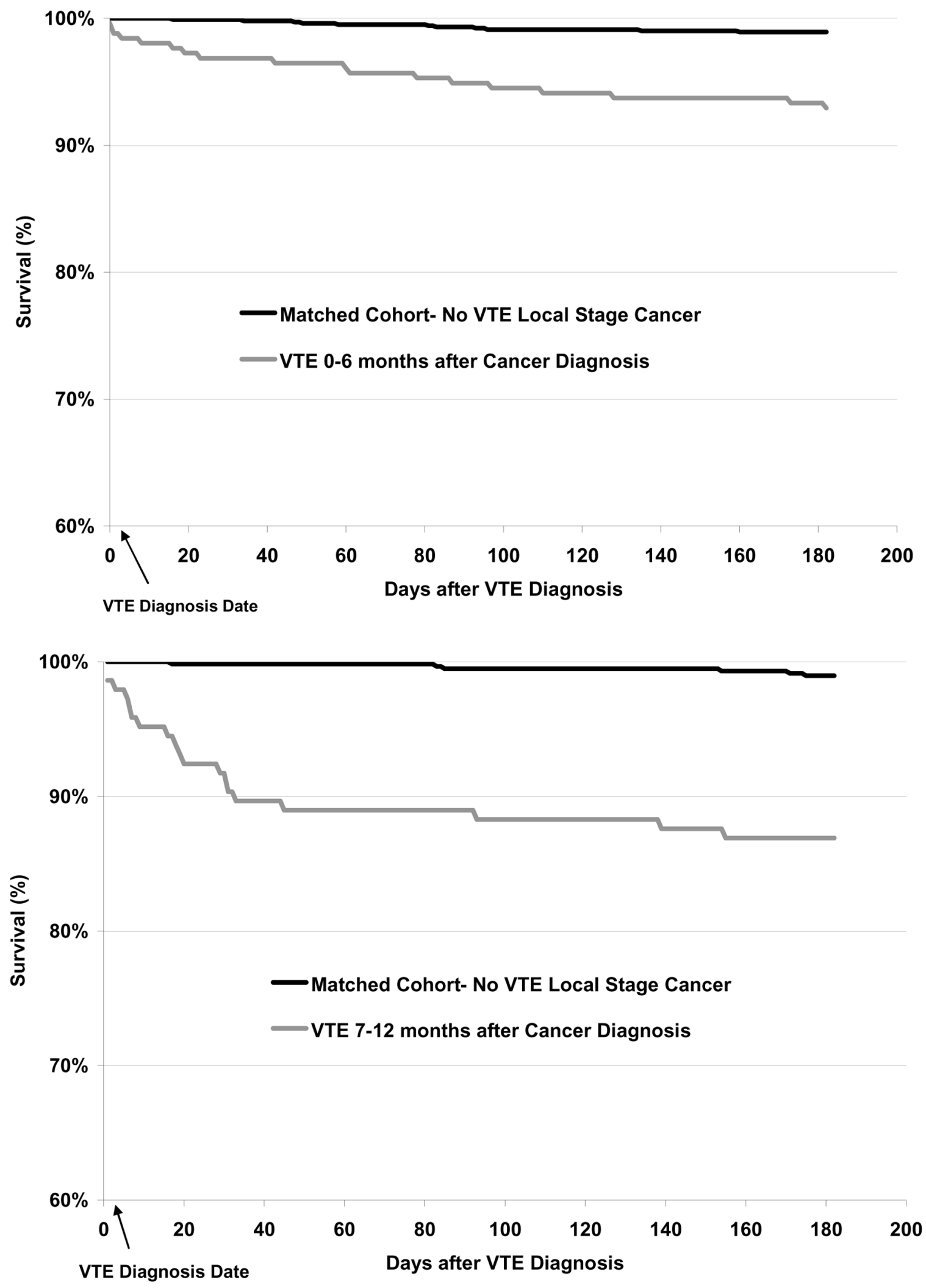

Best Pract Res Clin Haematol. Author manuscript; available in PMC 2010 March 01. 


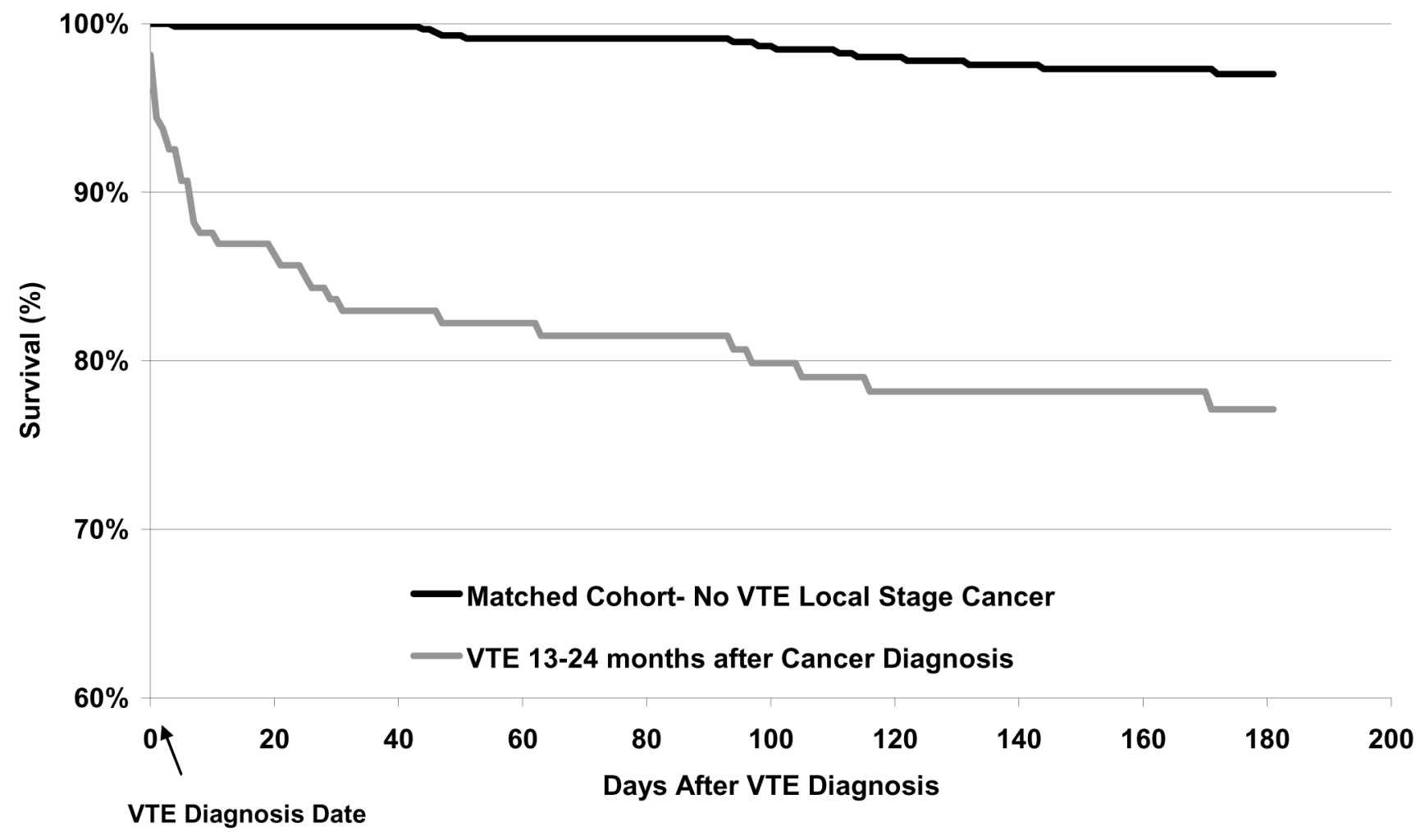

Figure 3.

Comparison of survival from the date of diagnosis of venous thromboembolism (VTE) among breast cancer patients who developed VTE at various time intervals after the diagnosis of local-stage breast cancer vs a matched sample of cases who were not diagnosed with VTE. 


\section{Table 1}

Venous thromboembolism (VTE) associated with specific types of cancer.

\begin{tabular}{|l|l|c|l|l|}
\hline Cancer & $\begin{array}{l}\text { California: cumulative } \\
\text { incidence of VTE } \\
\mathbf{1} \text { year }(\boldsymbol{n})\end{array}$ & $\begin{array}{l}\text { California: rate of } \\
\text { VTE (/100 patient- } \\
\text { years) }\end{array}$ & $\begin{array}{l}\text { Netherlands: } \\
\text { cumulative incidence } \\
\mathbf{6} \text { months }(\boldsymbol{n})\end{array}$ & $\begin{array}{l}\text { USA: hospitalized } \\
\text { Medicare patients, } \\
\text { prevalence 6 months }(\boldsymbol{n})\end{array}$ \\
\hline Pancreas & $5.3 \%(6524)$ & $14.0 \%$ & $2.3 \%(1674)$ & $1.2 \%(41551)$ \\
\hline Brain & $6.9 \%(3775)$ & $11.1 \%$ & $3.2 \%(1058)$ & $1.2 \%(13529)$ \\
\hline Acute myelogenous leukaemia & $3.7 \%(2292)$ & $7.4 \%$ & $1.9 \%(532)$ & - \\
\hline Stomach & $4.5 \%(5766)$ & $7.4 \%$ & $1.5 \%(2337)$ & $0.9 \%(32655)$ \\
\hline Oesophagus & $3.6 \%(2491)$ & $5.8 \%$ & $1.3 \%(1040)$ & $0.4 \%(14742)$ \\
\hline Renal cell & $3.5 \%(4891)$ & $4.3 \%$ & $1.3 \%(1503)$ & $0.8 \%(34375)$ \\
\hline Lung & $2.4 \%(44497)$ & $4.3 \%$ & $1.4 \%(9336)$ & $0.6 \%(232764)$ \\
\hline Ovary & $3.3 \%(5707)$ & $4.2 \%$ & $3.3 \%(1444)$ & $1.2 \%(26406)$ \\
\hline Liver & $1.7 \%(2312)$ & $4.1 \%$ & $0.7 \%(970)$ & $0.7 \%(22938)$ \\
\hline Lymphoma & $2.8 \%(9003)$ & $3.7 \%$ & $2.0 \%(2470)$ & $1.0 \%(52042)$ \\
\hline Chronic lymphocytic leukaemia & $2.7 \%(2023)$ & $3.1 \%$ & $1.7 \%(524)$ & - \\
\hline Acute lymphocytic leukaemia & $2.6 \%(1058)$ & $3.1 \%$ & $1.7 \%(168)$ & - \\
\hline Colon & $2.3 \%(32611)$ & $2.7 \%$ & $1.3 \%(6262)$ & $0.8 \%$ \\
\hline Chronic myelogenous leukaemia & $1.5 \%(951)$ & $1.8 \%$ & $0.6 \%(165)$ & - \\
\hline Bladder & $1.5 \%(7138)$ & $1.7 \%$ & $1.3 \%(2250)$ & $0.2 \%(168832)$ \\
\hline Uterus & $1.6 \%(8721)$ & $1.7 \%$ & $1.1 \%(1431)$ & $0.4 \%(11606)$ \\
\hline Prostate & $0.9 \%(51362)$ & $1.0 \%$ & $0.9 \%(6013)$ & $0.5 \%(218743)$ \\
\hline Breast & $0.9 \%(44707)$ & $0.9 \%$ & $0.8 \%(10566)$ & $0.2 \%(186273)$ \\
\hline Melanoma & $0.5 \%(9497)$ & $0.5 \%$ & $0.3 \%(2236)$ & - \\
\hline
\end{tabular}


Table 2

Comparison of the incidence of venous thromboembolism (VTE) based on initial cancer stage.

\begin{tabular}{lccc}
\hline Cancer & $\begin{array}{c}\text { Incidence rate of VTE in year after cancer diagnosis (events/100 patients) } \\
\text { Local stage }\end{array}$ & $\begin{array}{c}\text { Regional stage } \\
\text { Remote stage }\end{array}$ & 19.7 \\
Pancreas & 4.3 & 5.3 & 12.9 \\
Stomach & 2.7 & 3.9 & 8.0 \\
\hline Kidney & 1.2 & 3.9 & 7.6 \\
\hline Bladder & 0.7 & 2.7 & 6.2 \\
\hline Uterus & 0.9 & 1.6 & 5.2 \\
\hline Lung & 1.1 & 2.3 & 4.6 \\
\hline Colon/rectum & 0.9 & 2.3 & 4.6 \\
\hline Melanoma & 0.2 & 1.0 & 3.8 \\
\hline Ovary & 0.6 & 2.1 & 2.9 \\
\hline Lymphoma & 2.0 & 3.5 & 2.8 \\
\hline Breast & 0.6 & 1.0 & \\
\hline
\end{tabular}




\section{Table 3}

Effect of venous thromboembolism (VTE) on survival of patients with different cancer types, stratified by initial Surveillance, Epidemiology and End Results (SEER) cancer stage, and adjusted for age, race and gender.

\begin{tabular}{|l|l|l|l|}
\hline \multicolumn{2}{|l}{ Hazard ratio for death within 1 year among cases with VTE diagnosed in Year 1 vs no VTE (95\% confidence interval), adjusted for } \\
age, race and gender \\
\hline \multirow{2}{*}{ Cancer type } & \multicolumn{3}{|c|}{ Initial stage } \\
\cline { 2 - 4 } & Local & Regional & Metastatic \\
\hline Prostate & $5.6(3.8-8.5)^{\xi}$ & $4.7(1.9-11.5)^{\xi}$ & $2.8(1.5-5.0)^{\dagger}$ \\
\hline Breast & $6.6(3.7-11.8)^{\xi}$ & $2.4(1.3-4.5)^{\dagger}$ & $1.8(1.1-2.9)^{*}$ \\
\hline Lung & $3.1(2.1-4.5)^{\xi}$ & $2.9(2.3-3.5)^{\xi}$ & $2.5(2.3-2.7)^{\xi}$ \\
\hline Colon/rectum & $3.2(1.8-5.5)^{\xi}$ & $2.2(1.7-3.0)^{\xi}$ & $2.0(1.7-2.4)^{\xi}$ \\
\hline Melanoma & $14.4(4.6-45.2)^{\xi}$ & N/A & $2.8(1.5-5.3)^{\dagger}$ \\
\hline Non-Hodgkin's lymphoma & $3.2(1.9-5.3)^{\xi}$ & $2.0(1.3-3.2)^{\dagger}$ & $2.3(1.7-3.1)^{\xi}$ \\
\hline Uterus & $7.0(3.4-14.2)^{\xi}$ & $9.1(4.8-17.2)^{\xi}$ & $1.7(1.0-3.0)^{*}$ \\
\hline Bladder & $3.2(1.7-6.2)^{\xi}$ & $3.3(1.7-6.4)^{\xi}$ & $3.3(1.8-6.2)^{\xi}$ \\
\hline Pancreas & $2.3(1.2-4.6)^{*}$ & $3.8(2.8-5.1)^{\xi}$ & $2.3(1.9-2.7)^{\xi}$ \\
\hline Stomach & $2.4(1.1-5.1)^{*}$ & $1.5(1.0-2.1)^{*}$ & $1.8(1.4-2.3)^{\xi}$ \\
\hline Ovary & $11.3(2.5-51.7)^{\dagger}$ & $4.8(1.1-20.4)^{*}$ & $2.3(1.7-3.0)^{\xi}$ \\
\hline Kidney & $3.2(1.2-8.8)^{*}$ & $1.4(0.6-3.2)$ & $1.3(0.9-2.0)$ \\
\hline
\end{tabular}

Note: VTE was modelled as a time-dependent covariate.

N/A = Not enough VTE cases to estimate

${ }^{*} P<0.05$

${ }^{\dagger} P<0.01$.

$\xi_{P<0.001 .}$ 
Table 4

Predictors of development of venous thromboembolism in patients with cancer.

\begin{tabular}{|c|c|c|c|c|}
\hline Variable & Colon HR $(95 \%$ CI $)$ & Breast HR $(95 \% \mathrm{CI})$ & Glioma HR (95\% CI) & Ovarian HR (95\% CI) \\
\hline \multicolumn{5}{|l|}{ Gender } \\
\hline Female vs male & $1.0(0.9-1.1)$ & - & $0.8(0.7-0.9)^{\mathcal{S}}$ & - \\
\hline \multicolumn{5}{|c|}{ Age (versus < 45 years) } \\
\hline $45-64$ years & $1.1(0.9-1.3)$ & $1.4(1.2-1.8)^{\xi}$ & $2.4(1.9-3.0)^{\xi}$ & $1.9(1.3-2.6)^{\xi}$ \\
\hline $65-74$ years & $1.2(1.0-1.5)^{*}$ & $1.9(1.5-2.4)^{\xi}$ & $2.6(2.0-3.4)^{\mathcal{S}}$ & $1.8(1.3-2.6)^{\xi}$ \\
\hline$>75$ years & $1.0(0.9-1.2)$ & $2.0(1.6-2.6)^{\mathcal{S}}$ & $1.8(1.4-2.5)^{\mathcal{S}}$ & $1.5(1.0-2.2)^{*}$ \\
\hline \multicolumn{5}{|l|}{ Race (vs Caucasian) } \\
\hline Black & $0.9(0.8-1.1)$ & $1.3(1.0-1.5)^{*}$ & $0.8(0.6-1.2)$ & $1.3(1.0-1.8)$ \\
\hline Hispanic & $0.8(0.7-1.0)^{\xi}$ & $0.9(0.8-1.1)$ & $0.8(0.6-1.0)$ & $0.9(0.7-1.1)$ \\
\hline Asian-American & $0.4(0.3-0.5)^{\mathcal{S}}$ & $0.3(0.2-0.4)^{\xi}$ & $0.4(0.2-0.6)^{\mathcal{S}}$ & $0.8(0.5-1.1)$ \\
\hline \multicolumn{5}{|c|}{$\begin{array}{l}\text { Number of chronic co-morbidities }{ }^{\dagger} \text { (vs } \\
0)\end{array}$} \\
\hline 1 & $1.2 .(1.0-1.4)^{*}$ & $1.9(1.6-2.2)^{\mathcal{S}}$ & $2.3(1.9-2.8)^{\mathcal{\xi}}$ & $2.1(1.7-2.6)^{\xi}$ \\
\hline 2 & $1.5(1.3-1.8)^{\mathcal{S}}$ & $2.3(1.9-2.7)^{\mathcal{S}}$ & $2.8(2.2-3.5)^{\mathcal{S}}$ & $2.6(2.0-3.3)^{\mathcal{S}}$ \\
\hline 3 & $2.0(1.7-2.3)^{\xi}$ & $2.9(2.4-3.5)^{\mathcal{E}}$ & $3.5(2.8-4.3)^{\mathcal{S}}$ & $3.9(3.1-4.8)^{\mathcal{E}}$ \\
\hline \multicolumn{5}{|c|}{ Stage (vs local-stage cancer) } \\
\hline Regional & $2.1(1.8-2.4) \mathcal{S}$ & $2.1(1.8-2.3)^{\mathcal{S}}$ & N/A & $1.7(1.1-2.6)^{*}$ \\
\hline Metastatic & $3.2(2.8-3.8) \xi$ & $6.3(5.3-7.5)^{\xi}$ & N/A & $3.0(2.1-4.2)^{\xi}$ \\
\hline \multicolumn{5}{|c|}{ Major cancer surgery } \\
\hline Yes vs No & $0.4(0.3-0.4) \xi$ & $0.6(0.5-0.7) \xi$ & $1.7(1.3-2.3) \xi$ & $0.7(0.6-0.8) \xi$ \\
\hline
\end{tabular}

HR, hazard ratio; CI, confidence interval.

Follow-up time for ovary, breast and glioma $=2$ years; follow-up time for colon $=1$ year.

Examples: heart failure, chronic liver disease, chronic lung disease, paralysis, rheumatic disease

* $P<0.05$.

$\xi_{P<0.001}$ 